\title{
Analysis of invasive cervical cancer cases in Latvia
}

\author{
Anna Kornete $^{1 *}$, Elizabete Pumpure ${ }^{1}$, Ronalds Macuks ${ }^{1,2}$ \\ ${ }^{1}$ Department of Obstetrics and Gynecology, Riga Stradins University, Riga, Latvia \\ ${ }^{2}$ Oncology Centre of Latvia, Riga East Clinical University Hospital, Riga, Latvia
}

Received: 25 August 2016

Accepted: 24 September 2016

\section{*Correspondence:}

Dr. Anna Kornete,

E-mail: annakornete@gmail.com

Copyright: $\odot$ the author(s), publisher and licensee Medip Academy. This is an open-access article distributed under the terms of the Creative Commons Attribution Non-Commercial License, which permits unrestricted non-commercial use, distribution, and reproduction in any medium, provided the original work is properly cited.

\begin{abstract}
Background: The aim of the study is to evaluate the cervical cancer screening programme in Latvia and to determine how early cervical cancer diagnostics can be improved and the burden of the disease can be reduced.

Methods: All cervical cancer cases diagnosed in 2014 and treated in Oncology Centre of Latvia were included in the retrospective cross-sectional study. Cervical cancer cases were classified according to the cytological sampling interval: a "short" ( $<3$ years), a "regular" ( $3-5$ years) or a "long" ( $>5$ years) interval.

Results: There were 189 patients identified during the study period. Information was obtained from 130 (68.7\%) patients. $49.2 \%(\mathrm{n}=64)$ of all patients had had a cytological examination within the last three years. For $11.6 \%(\mathrm{n}=15)$ women, the screening interval was regular, while $21.5 \%(\mathrm{n}=28)$ had had their last cytological examination more than five years before. $17.7 \%(n=23)$ had never had cytological examination. A tendency for more frequent early stage cervical cancer detection in the group of cytological sampling interval less than three years compared to a 3-5 years interval $(71.9 \%$ vs. $53.3 \%, \mathrm{p}=0.003)$ was observed.

Conclusions: In Latvia, cervical cancer is an unresolved healthcare issue for women. Despite the fact that lack of a quality management system, diagnostic imperfections and non-attendance in the organized, cytology-based screening programme remain the main barrier of cervical cancer control, introduction of a more sensitive test, such as primary testing for oncogenic human papilloma virus types, could significantly reduce the burden of the disease.
\end{abstract}

Keywords: Invasive cervical cancer, Screening programme, Cytology, Human papilloma virus

\section{INTRODUCTION}

Cervical cancer was the fourth most commonly diagnosed cancer in women in 2012, with an estimated 527,600 new cases worldwide. ${ }^{1,2}$ High-risk regions (annual rates per 100,000 women in brackets) include Eastern (42.7) Africa, rates are lower in Europe-Sweden (9.7), but the lowest in Western Asia (4.4). ${ }^{1,2}$ The disease causes approximately 266,000 cases of death worldwide annually, accounting for $7.5 \%$ of all female cancer deaths. ${ }^{1,2}$ Mortality varies 18 -fold between the different regions of the world, with rates ranging from less than 2 per 100,000 in Western Asia to more than 27 per 100,000 in Eastern Africa. ${ }^{1,2}$ The large geographic variation in the morbidity and mortality rates of cervical cancer reflects differences in prevalence of risks factors, as well as persistent absence or inadequate implementation of cervical cancer screening programmes.

In several Western countries, where screening programmes have been long established, cervical cancer rates have decreased by as much as $65 \%$ over the past four decades. ${ }^{1}$ In contrast to the favorable overall trends, cervical cancer rates have been reported to be rising in Uganda and in some countries of Eastern Europe, as well as in Latvia. ${ }^{1,3}$ 
Latvia is the country with one of the highest cervical cancer incidance and mortality rates in Europe. Cervical cancer is the second most common cancer in women before 45 years of age. ${ }^{3}$ Over the past 10 years, the incidence of cervical cancer in Latvia has increased by $60 \%$. $^{3}$ Nationwide in 2014, the incidance of cervical cancer was 25.1 , while the mortality was 10.3 per $100,000 .^{3}$ Almost half of the newly diagnosed cervical cancer cases in Latvia are detected in late stage, although it is clear that with early diagnostics and appropriate treatment these malignancies can be eliminated entirely in precancerous stage. Furthermore, early and precisely diagnostics and treatment of the disease can save the reproductive function, quality of life and prolong survival. According to the World Bank's ranking 2014, Latvia is among the highly developed countries. ${ }^{4}$ Cervical cancer morbidity and mortality rates in Latvia do not match the level of national welfare.

Despite on fact that organized, cytology-based cervical cancer screening programme in Latvia have been in place since 2009 , it is not fully implemented and does not yield the desired result. The majority of new cervical cancer cases are detected in late stage and the rates of incidence and mortality attributed to the disease are still high.

The current study used a systematic approach to evaluate the cervical cancer screening programme in Latvia and to determine how early cervical cancer diagnostics can be improved and the burden of disease can be reduced.

\section{METHODS}

All cervical cancer cases diagnosed from January through December in 2014 and treated in Oncology Centre of Latvia were included in the retrospective cross-sectional study. In the first part of the research, the cases were identified through an ongoing programme that regularly gathers information on all new cases of cervical cancer. Afterwards patients' data from their medical documentation were analyzed. Verification of invasion was based on biopsy or hysterectomy reports, and staging was based on the FIGO staging system for cervical cancer. According to the FIGO, early stage cervical cancer is defined as stage IA1, IA2, IB1 and IIA2, while late stage or invasive cancer is defined as stage IB2, IIA1, IIB, IIIA, IIIB, IVA and IVB. Since cancer stage in medical documentation for $40.8 \%$ of the cases was not determined precisely according to the FIGO classification, and data compiled by the Centre for Disease Prevention and Control (CDPC) of Latvia statistics did not take into account the specific cancer classification, the current study deploys simplified classification. Early stage cervical cancer is defined as the FIGO stage I, while late or invasive cancer is defined as the FIGO stage II, III or IV.

In the second part of the research, the authors requested patients' permission and invited them to fill in a questionnaire during their follow-up. Of the 189 eligible patients, information was obtained from 130 (68.7\%). Reasons for non-participation were as follows: 17 (9.0\%) patients' refusals, 37 (19.6\%) patients could not be located, $5(2.7 \%)$ patients had deceased. Patients were divided in groups according to their place of residence, depending on whether they live in an urban (population of at least 2,000) or a rural area. Cervical cancer cases were classified according to the cytological sampling intervals: a "short" interval was defined when sampling was performed within the last three years; a "regular" interval was defined when sampling was performed once in a 3-5 years interval and a "long" interval when sampling was performed less frequently than once in a five years. ${ }^{5}$ Statistical data were analyzed with professional statistical data programme IBM SPSS Statistics.

\section{RESULTS}

According to the CDPC of Latvia, in 2014270 cervical cancer cases were identified in the country, from those $189(70.0 \%)$ were treated in Oncology Centre of Latvia. From the 228 newly diagnosed cervical cancer cases with determined stage, $104(45.6 \%)$ cases fell into the FIGO stage I, $15(11.0 \%)$ cases-into stage II, 54 (23.7\%) casesinto stage III and $45(19.7 \%)$ cases-into stage IV. Division according to time-scale of cancer diagnosis cervical cancer cases in 2014 in Latvia, was as follows: $104(38.5 \%)$ patients were diagnosed within early stage, while $124(45.9 \%)$ patients within late stage. Medical files of $42(15.6 \%)$ patients contained no data regarding spread of the cancer and therefore it was impossible to include these cases in any of above stated groups.

$56.9 \%(n=74)$ from 130 cancer cases of the second part of the study were attributed to the FIGO stage I, $9.3 \%$ $(\mathrm{n}=12)$ cases- to stage II, $21.5 \%(\mathrm{n}=28)$ cases- to stage III and $12.3 \% \quad(n=16)$ cases- to stage IV. $56.9 \%$ cervical cancer cases were diagnosed within early stage, while $43.1 \%$-within late stage. Stage was determined precisely according to the FIGO only in $59.2 \%(n=77)$ cases.

Among participants included in the study, following histological types of cancer were observed: $117(90.0 \%)$ squamous cell carcinomas, $11(8.5 \%)$ adenocarcinomas and two $(1.5 \%)$ other morphological types (small cell neuroendocrine cancer and primary cervical melanoma). Cancer stage group distribution by histological type of cancer is equal to squamous cell carcinomas and adenocarcinomas group $(\mathrm{p}=0.184)$.

Patients' mean age in the early stage cervical cancer group was $47.2 \pm 13.5$ years, while in the invasive cancer group it was $51.6 \pm 14.3$ years. In the age group above 39 years, the incidence of invasive cervical cancer rapidly grows, while in the age group above 49 years early diagnosed cervical cancer incidence decreases $(p=0.009)$.

Annual prophylactic visit to a gynecologist, as well as visit once in a three years for cytology-based screening 
provided an opportunity to diagnose cervical cancer in early stage $(\mathrm{p}<0.001)$ (Figure 1$)$. Cervical cancer was detected more often in early stage in cases cervical cytological smear had been taken during gynecological examinations $\quad(p=0.008)$. Though $42.9 \% \quad(n=24)$ of invasive cervical cancer cases had been diagnosed among women who had had either annual visit to a gynecologist or visit once in a three years.

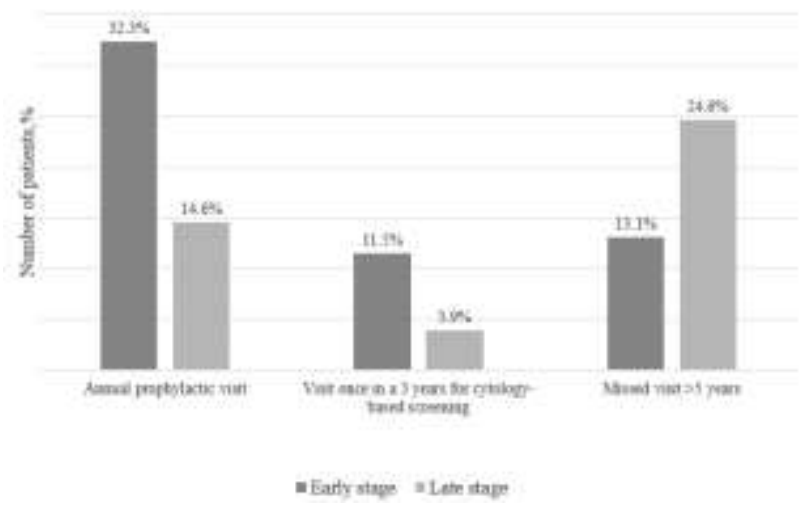

Figure 1: The association between regularity of the gynecological visit and the stage of cervical cancer.

$51.4 \%(n=38)$ of early stage cervical cancer cases were diagnosed during annual prophylactic visits to a gynecologist, while $62.5 \% \quad(n=35)$ of invasive cervical cancer cases were identified due to cervical cancer complaints $(\mathrm{p}<0.001)$ (Figure 2).

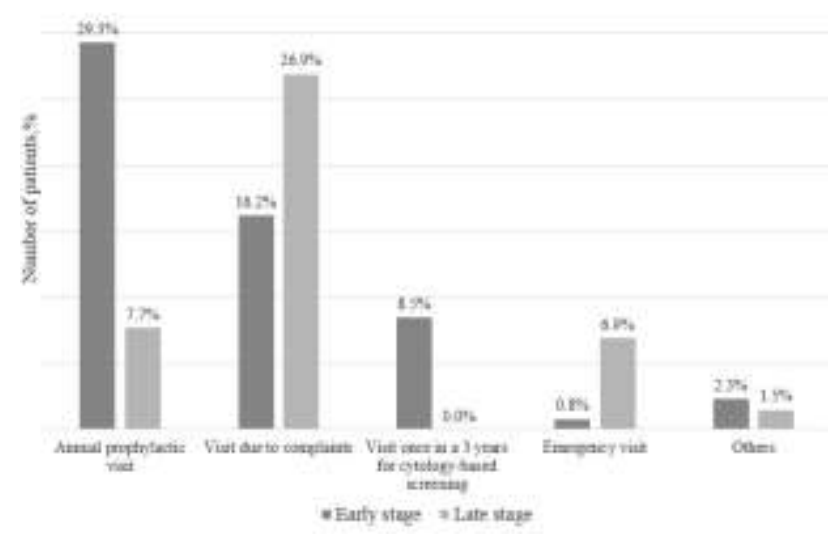

Figure 2: The association between the manner of diagnostics and the stage of cervical cancer.

$66.2 \%(n=49)$ patients who had been diagnosed early had no symptoms at the time when the diagnosis was set, while $20.3 \%(n=15)$ of those patients had had symptoms for at least a month $(\mathrm{p}<0.001)$. 17.9\% $\quad(n=10)$ of respondents with invasive cervical cancer at the time of diagnostics had had no complaints, while $64.3 \%(n=36)$ had had symptoms for a month or longer.

49.2\% ( $\mathrm{n}=64)$ of all patients had had a cytological examination within the last three years. For $11.6 \%(n=15)$ women the cytological screening interval had been regular, while $21.5 \%(n=28)$ had had their last cytological examination more than five years before. $17.7 \%(n=23)$ had never had cytological examination (Table 1). A tendency for more frequent early stage cervical cancer detection in the group of cytological sampling interval less than three years compared to the 3-5 years interval $(71.9 \%$ vs. $53.3 \%)(p=0.003)$ was observed. In the group of long cytological sampling interval early stage cervical cancer was diagnosed only in $32.1 \%(n=9)$ of patients (compared to a regular interval $\mathrm{p}=0.290$ ).

Table 1: The association between the cytological sampling interval and the stage of cervical cancer.

\begin{tabular}{|llllll|}
\hline & $\begin{array}{l}\text { Short } \\
\text { interval } \\
(<3\end{array}$ & $\begin{array}{l}\text { Regular } \\
\text { interval } \\
(3-5\end{array}$ & $\begin{array}{l}\text { Long } \\
\text { interval } \\
(>5\end{array}$ & $\begin{array}{l}\text { Never } \\
\text { sereened })\end{array}$ & Total \\
\hline $\begin{array}{l}\text { Early } \\
\text { stage }\end{array}$ & 46 & 8 & 9 & 11 & 74 \\
\hline $\begin{array}{l}\text { Late } \\
\text { stage }\end{array}$ & 18 & 7 & 19 & 12 & 56 \\
\hline Total & 64 & 15 & 28 & 23 & 130 \\
\hline
\end{tabular}

The patients' mean age at the time of diagnostics in the short interval group was $43.0 \pm 11.1$ years, in the regular interval group it was $45.0 \pm 0.8$ years, while in the long interval group it was $58.6 \pm 11.9$ years, in the neverscreened group it was $57.0 \pm 11.2$ years. The association between the patient's age and the cytological sampling interval is shown in Figure 3.

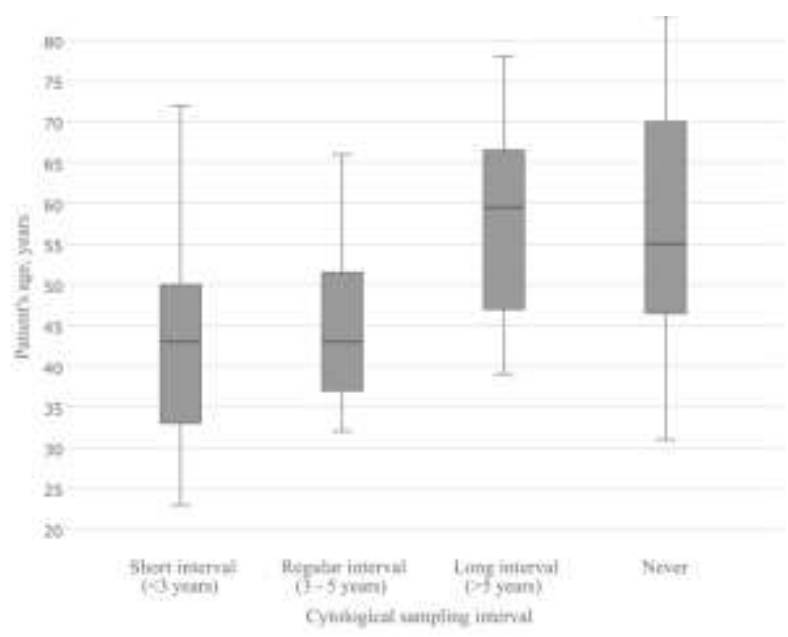

Figure 3: The association between the patient's age and the cytological sampling interval.

Most patients had become aware of the examination results when their gynecologist had informed them personally in case of identified abnormalities (41.5\%, $\mathrm{n}=54$ ) or patients had found out results themselves by contacting the specialist's office $(40.0 \%, \mathrm{n}=52)$. Only in $13.9 \%(n=18)$ of cases the specialist had informed the patient about the results whether abnormalities were found or not; $2.3 \%(n=3)$ of cases had found out results 
during their next visit and $2.3 \%(n=3)$ of cases had not had any communication with the gynecologist after the examination. $91(70.0 \%)$ of the 130 respondents were residing in urban areas, while $39(30.0 \%)$ were from rural areas.

Distribution of diagnosis of cancer stages (early vs. late stage) according to place of residency (urban vs. rural areas) was equable $(\mathrm{p}=0.045)$.

Only $63.9 \%(n=83)$ of patients had received an invitation letter to participate in the organized screening programme. Only $56.6 \% \quad(n=47)$ of those who had received the invitation letter participated in the organized screening programme.

\section{DISCUSSION}

In 2014 the majority of the new cervical cancer cases were diagnosed in late stage, although it is clear that the most cervical cancer cases may be prevented by an effective treatment of precancerous lesions detected in the organized screening programme. Furthermore, a similar trend can be observed in Latvia during recent years (Figure 4).

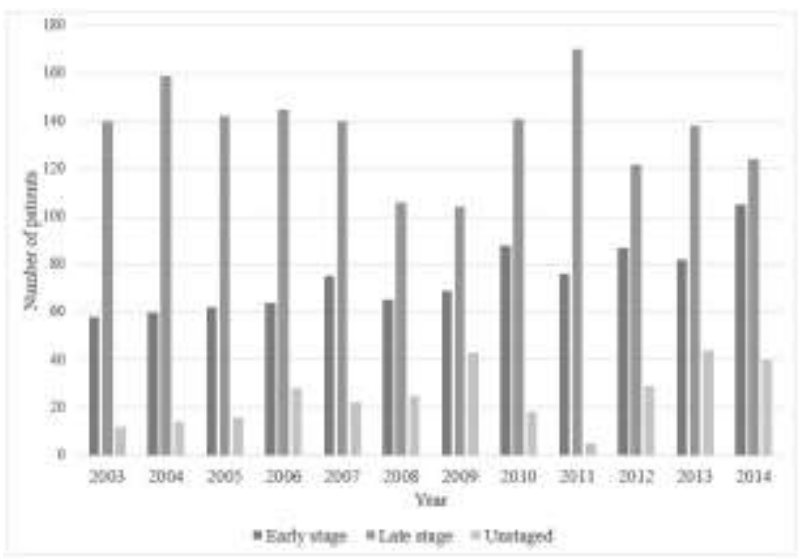

Figure 4: Distribution of cervical cancer stages from 2003 to 2014.

In Latvia, cervical cytological examination has been used since the 1960s. ${ }^{6}$ Historically, the Leishman methodology is applied, while elsewhere in the world the Papanikolau method prevails. ${ }^{6,7}$ Frequency of false positive and false negative results is equal for both methods. ${ }^{6}$ Thus, the cytological test result depends on quality of the material and qualification of the cytotechnologist. Studies have shown that improperly collected cytological smears are in fault for false negative or false positive results. ${ }^{6,7}$ In the current study, $42.9 \%(n=24)$ of invasive cervical cancer cases were detected in women who had had either annual visit to a gynecologist or visit once in a three years. For $32.2 \%(n=18)$ of patients to whom cancer was detected in late stage, the cytological examination interval was shorter than three years. These cases are candidates for rapidly progressive cancer category or diagnostic imperfections.

Screening programme management and supervisory bodies in the country should be established, and healthcare professionals must ensure the quality of each screening programme stage. Special efforts should be directed toward specialists' education in early and precisely diagnostics of cervical cancer. Improving the technical standards for performing and analyzing smears it could be possible to reduce the proportion of diagnostic imperfections. ${ }^{5}$ Cervical cytology testing should be performed only on samples analyzed in qualified laboratories and in compliance with international standards. ${ }^{8}$ According to European guidelines for quality assurance in cervical cancer screening the laboratory should perform a minimum of 10,000 tests per year, in Latvia it could be at least 5,000 tests per year. 6 Quality control measures such as annual testing of cytotechnologists, rescreening of random negative smears and analysis of individual screening and diagnostic smears in each case of invasive cervical cancer should be implemented. 6,9-11 Though at the moment this is not possible because samples are not preserved in case of negative result.

In January 2009, organized, cytology-based cervical screening programme was introduced in order to reduce the burden of the disease in Latvia. A personal invitation letter to attend to the organized screening programme is sent to all women aged 25 to 69 residing in the country every three years. The screening programme coverage in year 2014 was $27.8 \%$, and it had not reached the acceptable level of participation rate $(70 \%))^{8,12}$ In 2014 , 270 cases of cervical cancer were identified in Latvia, but only $6.6 \%$ of them within the organized screening programme. $^{3}$

The main strategy of improving the efficiency of the organized cervical cancer screening programme is enhancement of its coverage. There is need for greater patient participation in the organized rather than the opportunistic screening programme, which can be achieved by performing cytological examination only in accordance with the invitation letter. The opportunistic screening is associated with underuse of screening capacity in the target population, and too intensive cytological sampling in the rest of the population. ${ }^{8-10}$ Taking analysis within the organized screening programme, there is another advantage. In cases abnormal changes are detected, there is no restriction on the subsequent service to receive examination and treatment.

Establishment of an effective invitation system could increase attendance in the organized screening programme. A personal invitation letters that contain a scheduled appointment (date, time and place) are more effective than an invitation with open appointments. ${ }^{8,10}$ Women who do not participate in the organized screening 
programme should receive a personal reminder (by letter or by telephone). ${ }^{8,10}$ Responsiveness to invitation could be increased by improving the invitation letters' form and language (translation in the patient's native language). Furthermore, the patients should be informed about the possibility of restoring a lost invitation letter.

It is necessary to improve communication between the patient and the gynecologist. Specialists should inform patients about the results of the examination whether abnormalities were found or not, thus providing clear guidance on the future tactics. Patients and gynecologists should establish link with family physicians to support follow-up of cervical cancer. A follow-up programme linked to the regular health check-up visits provides an opportunity for continued engagement with women. In particular, it refers to older women due to the fact that they are no longer in reproductive age therefore unlikely to visit gynecologist for check-up visits.

Special effort should be directed toward women's education. By providing information about attending to the organized screening programme and adhering to local protocol on follow-up and treatment in case when abnormalities are detected, health care providers can help to ensure that women can make an informed decision. ${ }^{8,10}$ That is the key to promoting high compliance throughout the entire screening process.

The authors of the research raise the idea that in case of compulsory health insurance in Latvia, women would have to participate in the organized screening programme according to the schedule.

According to the current study results there is a significant difference in mean age among patients in the short and the long screening interval groups, respectively $43.0 \pm 11.07$ and $58.6 \pm 11.94$ years. In age group above 39 years, incidence of invasive cervical cancer rapidly grows, while in age group above 49 years early diagnosed cervical cancer incidence decreases. Hence the finding suggests that a large number of older women do not receive this important part of routine preventive medical care, thus cervical cancer screening efforts in older women must be intensified.

Effectiveness using primary testing for the DNA of oncogenic human papilloma virus (HPV) types in cervical cancer screening has been proven. ${ }^{8-10}$ Significant benefits of HPV primary screening compared to cytology primary screening include: higher sensitivity in detecting precancerous cervical lesions; increased protection against cervical cancer and reduced the burden of grade 2 cervical intraepithelial neoplasia or more severe neoplasia (CIN2+), reflecting earlier detection of persistent precancerous lesions. ${ }^{8,11}$ However, there are also potential harms of HPV primary screening including: significantly increased positive test rates, colposcopy referrals and biopsies, and over diagnosis of non-progressive CIN2+ lesions. ${ }^{8-11}$ These potential harms can be greatly reduced or avoided if appropriate screening policy and programme organization are applied..$^{8-11,13}$ To control the considerable potential for over diagnosis and overtreatment in HPV primary screening, particularly in women under 35 years, cervical screening programmes using HPV primary testing must adopt specific policies for management through triage. ${ }^{8-11,13}$ Cytological triage is defined as testing HPV positive women for cytology and referring directly to colposcopy those women who show relevant cytological abnormalities. ${ }^{8,11,14}$ There is also evidence that cytology informed of HPV positivity is more sensitive than cytology without knowing the presence of HPV infection. $8,11,14$

The screening interval for women with a negative HPV primary test result should be at least five years and may be extended up to 10 years depending on the age and screening history. ${ }^{8,14}$ Prolonged intervals for HPV primary screening would reduce costs and, more importantly, would reduce the probability of unnecessary colposcopy and treatment with attendant side effects. ${ }^{8,14}$ There is good evidence from randomized trials that the low-risk period is longer after a negative HPV test than after normal cytology. $8,11,14$

In the implementation of HPV primary screening it is also important to keep the entire screening process in mind, including the attendant laboratory, colposcopy, cytopathology and histopathology services. Like cervical cytology testing, HPV testing should be performed only on samples processed and analyzed in qualified laboratories, accredited by authorized accreditation bodies and in compliance with international standards. The laboratory should perform a minimum of $10,000(5,000)$ tests per year. ${ }^{8,13,15}$ Cervical cancer screening programmes should adopt a HPV primary test for use only if it has been validated by demonstrating reproducible, consistently high sensitivity and minimal detection of clinically irrelevant, transient HPV infections. ${ }^{9,14-16}$

While HPV primary screening has been shown to be more effective than cytology primary screening in reducing the incidence of cervical cancer from age of 35 years, the only primary screening test currently recommended for cervical cancer screening in women under 35 years of age is cytology., ${ }^{8,19}$

The authors of the study are considering primary testing for oncogenic HPV types might enhance organized screening program's coverage due to the fact that women have a greater initiative for a more accurate test.

\section{CONCLUSION}

In Latvia, cervical cancer is an unresolved healthcare issue for women. Despite the fact that lack of a quality management system, diagnostic imperfections and nonattendance in the organized screening programme remain the main barrier of cervical cancer control, introduction of a more sensitive test, such as primary testing for oncogenic HPV types, could significantly reduce the burden of the disease. 
Funding: No funding sources

Conflict of interest: None declared

Ethical approval: The study was approved by the Institutional Ethics Committee

\section{REFERENCES}

1. American Cancer Society. Global Cancer Facts and Figures 3rd Edition, 2015. Available at http://www.cancer.org/acs/groups/content/@ research /documents/document/acspc-044738.pdf. Accessed 12 December 2015.

2. Ferlay J, Soerjomataram I, Ervik M, Dikshit R, Eser $\mathrm{S}$, Mathers C. Cancer incidence and mortality worldwide: Sources, methods and major patterns in GLOBOCAN 2012. Int J Cancer. 2015;136:359-86.

3. The Centre for Disease Prevention and Control. Statistical Yearbook of Health Care in Latvia 16th edition, 2015. Available at file:///C:/Mani\%20Dokumenti/Lejupielades/0_Ievads _saturs_2014.pdf. Accessed 4 November 2015.

4. The World Bank. World Development Indicators 2014. Available at http://wdi.worldbank.org/tables. Accessed at 6 December 2015.

5. Janerich DT, Hadjimichael O, Schwartz PE, Lowell DM, Meigs JW, Merino MJ. The Screening Histories of Women with Invasive Cervical Cancer, Connecticut. Am J Public Health. 1995;85:791-94.

6. Viberga I, Engele L, Baili P. Past, present and future of the cervical cancer screening in Latvia. Tumori. 2010;96:529-37.

7. Naucler P, Ryd W, Törnberg S, Strand A, Wadell G, Elfgren K. Human papillomavirus and Papanicolaou tests to screen for cervical cancer. N Engl J Med. 2007;357:1589-97.

8. Von Karsa L, Arbyn A, De Vuyst H, Dillner J, Dillner L, Franceschi S. Executive summary. In: European guidelines for quality assurance in cervical cancer screening. Second edition, Supplements. Anttila A, Arbyn A, De Vuyst H, Dillner J, Dillner L, Franceschi S, et al (eds.). Office for Official Publications of the European Union, Luxembourg, 23-174.

9. Cuzick J, Clavel C, Petry K. Overview of the European and North American studies on HPV testing in primary cervical cancer screening. Int $\mathrm{J}$ Cancer. 2006;119:1095-01.

10. Massad LS, Einstein MH, Huh WK, Katki HA, Kinney WK, Schiffman M. Updated Consensus Guidelines for the Management of Abnormal
Cervical Cancer Screening Tests and Cancer Precursors. J Low Genit Tract Dis. 2013;17:1-27.

11. Moss S, Gray A, Legood R, Vessey M, Patnick J, Kitchener $H$. Effect of testing for human papillomavirus as a triage during screening for cervical cancer: observational before and after study. BMJ. 2006;332:83-5.

12. The National Health Service. Vēža savlaicīgas atklāšanas programmas rezultāti 2015. Available at http://www.vmnvd.gov.lv/lv/469-veselibas-aprupespakalpojumi/veza-savlaicigas-atklasanasprogramma/626-veza-savlaicigas-atklasanasprogrammas-rezultati. Accessed 1 February 2016.

13. TOMBOLA Group. Cytological surveillance compared with immediate referral for colposcopy in management of women with low grade cervical abnormalities: multicenter randomized controlled trial. BMJ. 2009;339:2546-57.

14. Wentzensen N, Schiffman M, Palmer T, Arbyn M. Triage of HPV positive women in cervical cancer screening. J Clin Virol. 2016;6:49-55.

15. Tidy J, Luesley D, Bowring J. NHS Cervical Screening Programme Colposcopy and Programme Management. PHE publications. 2016;20:1-108.

16. Lorincz AT, Brentnall AR, Scibior-Bentkowska D, Reuter C, Banwait R, Cadman L. Validation of a DNA methylation HPV triage classifier in a screening sample. Int J Cancer. 2016;138:2745-51.

17. Ronco G, Giorgi-Rossi P, Carozzi F, Dalla Palma P, Del Mistro A, De Marco L. Human papillomavirus testing and liquid-based cytology in primary screening of women younger than 35 years: results at recruitment for a randomised controlled trial. Lancet. 2006; 7:547-55.

18. Sasieni P, Adams J, Cuzick J. Benefit of cervical screening at different ages: evidence from the UK audit of screening histories. Br J Cancer. 2003;89:8893.

19. Skinner SR, Wheeler CM, Romanowski B, Castellsagué X, Lazcano-Ponce E, Del RosarioRaymundo MR. Progression of HPV infection to detectable cervical lesions or clearance in adult women: Analysis of the control arm of the VIVIANE study. Int J Cancer. 2016;138:2428-38.

Cite this article as: Kornete A, Pumpure E, Macuks R. Analysis of invasive cervical cancer cases in Latvia. Int J Reprod Contracept Obstet Gynecol 2016;5:3789-94. 